\title{
PENGEMBANGAN MULTIMEDIA PEMBELAJARAN BERBASIS MACROMEDIA FLASH PADA MATERI BANGUN DATAR
}

\author{
Ari Septian $^{1 *}$, Sarah Inayah ${ }^{2}$, Jeni Irpan Pelani ${ }^{3}$ \\ 1,2,3 Universitas Suryakancana \\ *ariseptian@unsur.ac.id
}

Diterima: 24 September 2020 Disetujui: 12 November 2020 Dipublikasikan: 31 Januari 2021

\begin{abstract}
ABSTRAK
Penggunaan multimedia dalam pembelajaran dapat membantu menyajikan informasi dalam bentuk yang menyenangkan, menarik dan jelas sehingga dapat meningkatkan kualitas pembelajaran. Terdapat banyak aplikasi yang dapat dimanfaatkan untuk mengembangkan multimedia pembelajaran, diantaranya macromedia flash. Macromedia flash merupakan aplikasi yang handal untuk digunakan dalam pembelajaran yang dapat dibuka menggunakan komputer, laptop dan handphone. Akan tetapi masih jarang guru yang menggunakan aplikasi tersebut. Penelitian ini bertujuan mengembangkan multimedia pembelajaran matematika di SMP dalam materi bangun datar dan mengetahui kelayakan multimedia pembelajaran dari berbagai validasi ahli media dan ahli materi dari dosen pendidikan matematika FKIP UNSUR serta Guru pendidikan matematika. Multimedia pembelajaran yang dikembangkan menyajikan materi, contoh soal, kuis dan gambar. Penelitian ini merupakan penelitian dan pengembangan dengan model ADDIE. Multimedia pembelajaran berbasis Macromedia flash ini dikembangkan berdasarkan validasi tiga orang ahli media dan tiga orang ahli materi. Berdasarkan hasil penelitian diperoleh bahwa multimedia pembelajaran matematika berbasis Macromedia flash menurut ahli media memenuhi kategori layak dengan persentase mencapai $78 \%$. Sedangkan menurut ahli materi memenuhi kategori layak dengan persentase mencapai $73 \%$. Secara rata - rata, multimedia pembelajaran matematika berbasis Macromedia flash ini memenuhi kategori layak dengan persentase mencapai $76 \%$ sehingga efektif sebagai multimedia pembelajaran matematika berbasis Macromedia flash dan bisa digunakan kapanpun.
\end{abstract}

Kata Kunci: Multimedia Pembelajaran Matematika, Macromedia flash, Bangun Datar, ADDIE.

\begin{abstract}
The use of multimedia in learning can help present information in a fun, interesting and clear form so that it can improve the quality of learning. There are many applications that can be used to develop multimedia learning, including macromdia flash. Macromedia flash is a reliable application for use in learning. Macromedia flash can be opened using computers, laptops and cellphones. However, teachers rarely use the application. This study aims to develop multimedia learning mathematics in junior high schools in flat shape materials and to determine the feasibility of multimedia learning from various validations of media experts and material experts from mathematics education lecturers, FKIP UNSUR and mathematics education teachers. The developed learning multimedia provides material, sample questions, quizzes and pictures. This research is a research and development model with ADDIE. This Macromedia flash-based learning multimedia was developed based on the validation of three media experts and three material experts. Based on the results of the study, it was found that the multimedia learning mathematics based on Macromedia flash according to media experts met the Eligible category with a percentage reaching $78 \%$. Meanwhile, according to the material expert, it meets the Eligible category with a percentage of up to $73 \%$. On average, this Macromedia flash-based multimedia learning multimedia meets the Eligible category with a percentage of up to $76 \%$ so it is effective as a Macromedia flash-based mathematics learning multimedia and can be used at any time.
\end{abstract}

Keywords: Mathematics Learning Multimedia, Macromedia flash, Two-dimentional figure, ADDIE. 


\section{Range: Jurnal Pendidikan Matematika Vol. 2 No. 2 Tahun 2021 Ari Septian, dkk.}

\section{Pendahuluan}

Media pembelajaran merupakan alat yang berfungsi untuk menyampaikan informasi. Ada berbagai bentuk informasi yang dapat disampaikan melalui media pembelajaran, baik berbentuk teks, gambar, grafis, foto, audio dan animasi. Media yang menggabungkan dua unsur atau lebih dari bentuk informasi tersebut secara terintegrasi disebut multimedia. Media atau multimedia pembelajaran memiliki konstribusi terhadap pengembangan dan peningkatan pembelajaran sebagai berikut: (1) penyampaian pesan pembelajaran dapat lebih terstandar, (2) pembelajaran dapat lebih menarik, (3) pembelajaran menjadi lebih interakif, (4) waktu pelaksaan pembelajaran dapat efesien, (5) kualitas pembelajaran dapat ditingkatkan, (6) proses pembelajaran dapat berlangsung kapanpun dan dimanapun diperlukan, (7) sikap positif siswa terhadap materi serta proses pembelajaran dapat ditingkatkan, dan (8) peran guru berubah ke arah yang positif (Hendriawan \& Septian, 2019; Masykur, Nofrizal, \& Syazali, 2017).

Multimedia terbagi menjadi dua kategori yaitu multimedia linier dan multimedia interaktif. Multimedia linier adalah suatu multimedia yang tidak dilengkapi dengan alat pengontrol apapun yang dapat dioperasikan oleh pengunaan seperti TV dan film. Sedangkan multimedia interaktif adalah suatu multimedia yang dilengkapi dengan alat pengontrol, sehingga pengguna dapat memilih apa yang dikehendaki untuk proses selanjutnya, seperti pembelajaran interaktif, aplikasi game dan lain-lain (Daryanto \& Karim, 2017; Seabra \& Almeida, 2015).

Pembelajaran dengan menggunakan media komputer mampu merangsang peserta didik dalam proses pembelajaran diantaranya mengerjakan latihan, melakukan kegiatan simulasi, dengan adanya animasi grafik, warna dan musik peserta didik lebih tertarik dan mudah memahami materi yang ingin disampaikan. Banyak sekali aplikasi-aplikasi komputer yang diluncurkan seperti Geogebra, Microsoft Powerpoint, Adobe Flash, Macromedia flash, dll yang seharusnya mampu dimanfaatkan oleh para pendidik di Indonesia (Septian, 2017; Septian \& Komala, 2019). Adapun media atau multimedia pembelajaran yang sesuai dengan perkembangan teknologi yaitu Macromedia flash. Macromedia flash adalah software yang menyajian dalam bentuk visual diantaranya seperti video, animasi, gambar dan suara untuk menarik minat dan bakat peserta didik agar lebih mudah memahami, mengingat serta menjawab soal-soal latihan sebagai memaksimalkan pemahaman materi.

Dalam proses pembelajaran akan ditemukan masalah, termasuk dalam pembelajaran matematika. Terdapat berbagai topik dalam pembelajaran matematika diantaranya mengenai bangun datar. Masalah yang sering dihadapi siswa dalam materi bagun datar yaitu menjawab soal sederhana, memahami gambar atau bentuk, sifat-sifat bangun datar dan rumus. Banyak siswa yang tidak mampu menjawab soal soal yang sederhana, misalnya hubungan antara persegi dan persegi panjang, persegi panjang dan jajargenjang, antara segitiga sama kaki, dan segitiga sama sisi. Sehingga dalam multimedia pembelajaran ini disajikan berupa sifat-sifat bangun datar, rumus-rumus, dan gambar yang dikemas dengan semenarik mungkin. Agar mempermudah untuk mengigat dan selain itu ditambahkan soal-soal agar siswa dapat berlatih secara mandiri. Oleh karena itu, pada penelitian kali ini peneliti memilih meneliti tentang materi bangun datar, karena materi ini merupakan salah satu materi yang ada di SMP. Materi ini juga sesuai untuk dikembangkan menggunakan media berbasis Macromedia flash. Adapun isi materi yang akan dibahas adalah bangun datar itu terdiriri dari segitiga, persegi, persegi panjang, jajar genjang, belah ketupat, layang-layang, lingkaran, dan trapesium. Oleh karena itu peneliti mengembangan Macromedia flash dengan masalah yang sering dihadapi siswa terhadap materi bangun datar (Masykur et al., 2017; Milovanović, Takači, \& Milajić, 2011).

Dalam penelitian ini perlu adanya rumusan masalah, sehingga terlihat jelas masalah yang akan diteliti, adapun rumusan masalah yaitu : (1) Bagaimana bentuk multimedia pembelajaran matematika berbasis Macromedia flash ? (2) Bagaimana validas teoritik pada multimedia pembelajaran matematika berbasis Macromedia flash yang dikembangkan? 


\section{Metode Penelitian}

Penelitian ini merupakan penelitian dan pengembangan atau Research and Development (R\&D) (Sugiyono, 2017) dengan model ADDIE (Analysis, Design, Development, Implementation, and Evaluation) (Widyastuti \& Susiana, 2019). Penelitian ini didasarkan pada analisis kebutuhan yakni kebutuhan peserta didik SMP akan kemajuan teknologi sekarang. Produk yang dihasilkan berupa multimedia pembelajaran matematika yang dikembangkan melalui Macromedia flash dengan format .SWF (Shock Wave Flash).

\section{Prosedur Pengembangan}

Dalam model pengembangan ADDIE terdapat lima langkah yakni Analisis (Analysis), Desain (Design), Pengembangan (Development), Implementasi (Implementation) dan Evaluasi (Evaluation). Dalam penelitian ini hanya dibatasi sampai tahap ketiga.

1. Analisis (Analysis)

Langkah pertama ini meliputi analisis kebutuhan, studi pustaka, studi literatur, penelitian skala kecil, dan standar laporan yang dibutuhkan. Kajian penelitian ini akan memusatkan penelitian tentang perancangan media pembelajaran berbasis Macromedia Flash dengan materi bangun datar. Penelitian ini akan dilaksanakan dengan menganalisa untuk mengetahui dan mengklarifikasi apakah masalah yang dihadapi memerlukan solusi berupa pembuatan media pembelajaran.

2. Desain (Design)

Desain awal dilaksanakan dengan beberapa langkah, meliputi: menentukan desain produk yang akan dirancang, menentukan sarana dan prasarana penelitian yang dibutuhkan selama proses penelitian dan perancangan serta menyusun instrumen untuk penilaian produk melalui validitas ahli. Subjek validitas dalam penelitian ini terbagi menjadi dua di antaranya ahli materi dan ahli media. Uji validitas Ahli media dan ahli materi masing masing terdiri dari 2 dosen pendidikan matematika dan 1 guru pendidikan matematika

3. Pengembangan (Development)

Pengembangan adalah proses pembuatan media pembelajaran yang sudah didesain dan direncanakan, langkah selanjutnya adalah memvalidasi media tersebut melalui ahli media maupun ahli materi. Dari validasi itu akan diketahui berapa presentase kategori kelayakan dari media yang telah dibuat. Kelemahan-kelemahan dan kekurangan-kekurangan yang telah ditemukan dalam validasi ahli, selanjutnya dicoba untuk dikurangi dengan cara merevisi atau memperbaiki desain. Sehingga hasil yang diperoleh semakin memuaskan sebelum dipublikasikan.

4. Implementasi (Implementation)

5. Evaluasi (Evaluation)

\section{Hasil Penelitian dan Pembahasan}

\section{Bentuk Multimedia Pembelajaran Matematika Berbasis Macromedia Flash}

Konten - konten dalam multimedia pembelajaran matematika berbasis Macromedia flash dengan materi bangun datar terdiri dari : contoh soal matematika, kuis matematika, tujuan materi ,dan materi matematika. Semua konten dalam multimedia pembelajaran ini bisa diakses secara offline. Dengan menggunakan komputer atau handphone. Berikut adalah bentuk dari multimedia pembelajaran matematika berbasis Macromedia flash: (a) Bagian Pembuka (Introduction). Pada bagian pembuka ini ditampilkan beberapa informasi awal berupa materi bangu datar dan registrasi untuk siswa yang di tunjukan pada Gambar 1. 


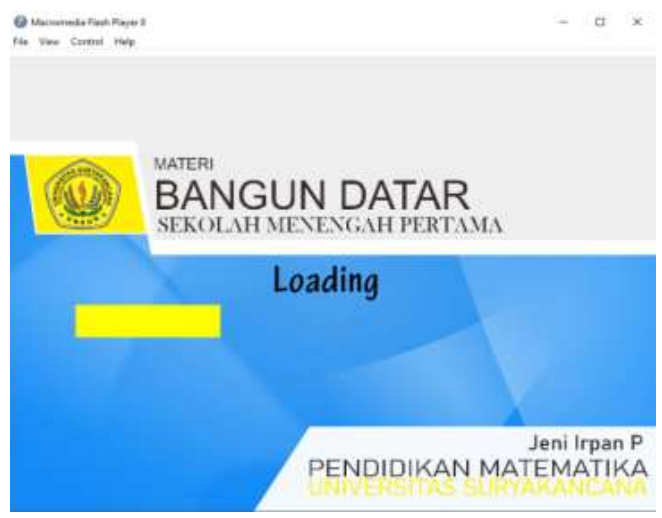

\section{Gambar 1. Tampilan Awal Multimedia Pembelajaran}

Berdasarkan Gambar 1. terdapat nama, kelas dan sekolah untuk mempermudah saat menginput. (b) Menu Utama (Home) Pada menu utama ini ditampilkan secara penuh tombol - tombol atau navigasi untuk mengakses konten - konten seperti tombol materi, latihan soal, kuis, tujuan materi yang ditunjukan pada Gambar 2.

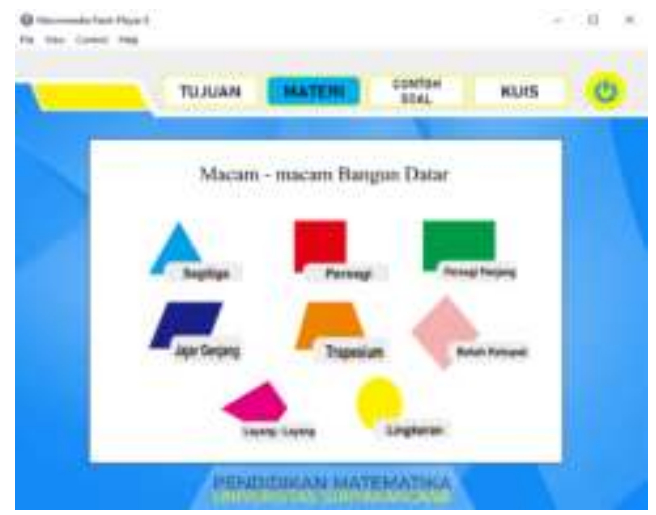

\section{Gambar 2. Tampilan Menu Multimedia Pembelajaran}

Berdasarkan Gambar 2. terdapat gambar kampus Universitas Suryakancana. (c) Tujuan. Pada menu tujuan ini ditampilkan tujuan pembelajaran dan pembuat multimedia pembelajaran. Yang di tunjukan pada Gambar 3.

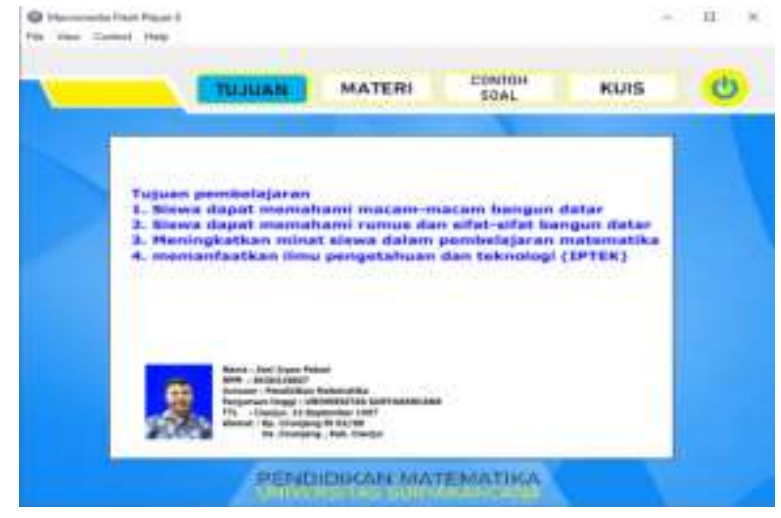

Gambar 3. Tampilan Menu tujuan Multimedia Pembelajaran 
Berdasarkan Gambar 3. menunjukan tujuan suatu pembelajaran yang akan dihasilkan siswa dan terdapat bio data pembuat. (d) Materi. Pada menu materi terdapat beberapa macam bangun datar dan didalamnya terdapat rumus, sifat dan bentuk seperti terlihat pada Gambar 4.

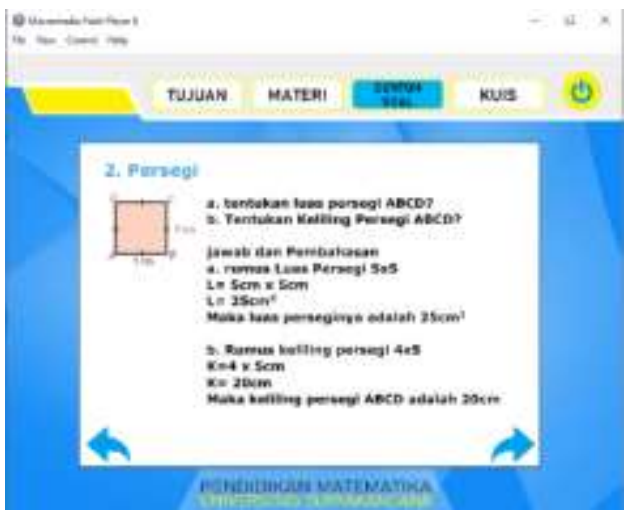

\section{Gambar 4. Tampilan Menu Materi Mutimedia Pembelajaran}

Berdasarkan Gambar 4. ini menunjukan materi diantaranya materi segitiga, persegi, persegi panjang, jajar genjang, trapesium, layang-layang, belah ketupat dan lingkaran. Materi ditamplkan beserta rumus rumus dan sifatnya. (e) Contoh Soal. Pada menu contoh soal terdapat tombol berbentuk panah kiri dan kanan gunanya untuk next dan back. Dalam menu contoh soal didalamnya berupa contoh soal yang berkaitan dengan materi dan beserta jawaban untuk memahami pembelajaran.

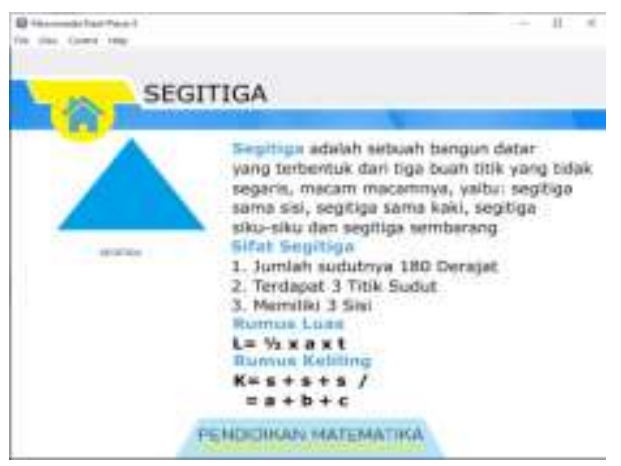

\section{Gambar 5. Tampilan Menu Contoh Soal Multimedia Pembelajaran}

Berdasarkan gambar 5 diatas menunjukan beberapa contoh soal beserta jawaban terdiri dari contoh soal persegi panjang, persegi , segitiga, lingkaran, layang-layang, belah ketupat, jajargenjang, dan trapesium. (f) Kuis. Pada menu kuis ini terdapat soal berbentuk Pilihan Ganda dan terdapat penjelasan atau aturan sebelum memulai, beserta hasil yang telah diperoleh.

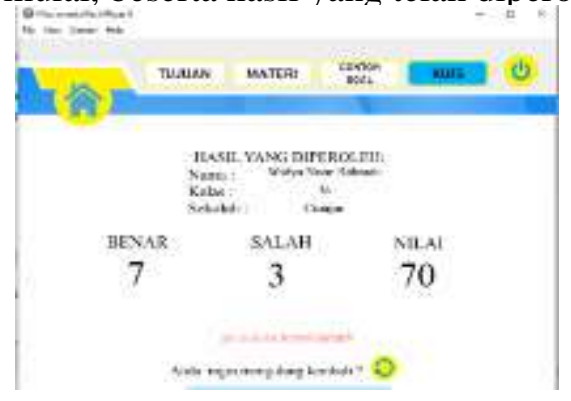

Gambar 6. Tampilan Menu Kuis Multimedia Pembelajaran 


\section{Range: Jurnal Pendidikan Matematika Vol. 2 No. 2 Tahun 2021 Ari Septian, dkk.}

Gambar 6. menunjukan soal dan hasil dari pengerjaan kuis tersebut. Sebelum multimedia pembelajaran matematika berbasis Macromedia flash ini divalidasi oleh para ahli baik itu ahli materi ataupun ahli media.

Validasi ahli digunakan untuk Pengujian atau penilaian multimedia pembelajaran matematika berbasis Macromedia flash yang dikembangkan dilakukan oleh enam ahli, tiga ahli materi dan tiga ahli media diantaranya dosen dua orang dan guru satu orang. Masing - masing ahli mengisi angket evaluasi yang telah disusun berdasarkan aspek - aspek yang telah ditentukan untuk dinilai. Dalam angket tersebut disediakan pula bagian isian untuk memberikan kritik dan saran pada multimedia pembelajaran matematika berbasis Macromedia flash yang dikembangkan. Data hasil penilaian dari ahli media dan ahli materi berupa kritik dan saran dapat dilihat pada Tabel 1. dan Tabel 2.

Tabel 1. Hasil Evaluasi oleh Ahli Media

\begin{tabular}{|c|c|}
\hline Validator & Kritik dan Saran \\
\hline $\begin{array}{c}\text { Ahli Media } 1 \\
\text { Ari Septian, S.Si, M.Pd. }\end{array}$ & Sudah Bagus \\
\hline \multirow{2}{*}{$\begin{array}{c}\text { Ahli Media } 2 \\
\text { Hedi Budiman, ST.,M.Pd }\end{array}$} & Perbaikan dalam penyesuaian musik \\
\hline & $\begin{array}{l}\text { Perbaikan dalam Penyesuaian musik dengan } \\
\text { volume }\end{array}$ \\
\hline \multirow{11}{*}{$\begin{array}{c}\text { Ahli Media } 3 \\
\text { M. Ardiansyah Hendriawan, } \\
\text { S.Pd }\end{array}$} & $\begin{array}{l}\text { Multimedia sebaiknya dapat digunakan diberbagai } \\
\text { platform baik itu PC ataupun Smartphone }\end{array}$ \\
\hline & $\begin{array}{l}\text { Multimedia sebaiknya mudah dibuka tanpa } \\
\text { aplikasi pihak ketiga }\end{array}$ \\
\hline & $\begin{array}{l}\text { Loading System pada Splashscreen kurang } \\
\text { sempurna, mungkin karena menggunakan aplikasi } \\
\text { pihak ketiga }\end{array}$ \\
\hline & $\begin{array}{l}\text { Pada Form Registrasi, kolom nama, kelas, dan } \\
\text { sekolah kurang rapih antara persegi panjang dan } \\
\text { kotak latar belakang berwarna putih }\end{array}$ \\
\hline & $\begin{array}{l}\text { Pada Form Registrasi, lebih baik diubah menjadi } \\
\text { Data Diri Siswa atau Data Diri Pengguna karena } \\
\text { pada bagian tersebut tidak menggunakan System } \\
\text { Login }\end{array}$ \\
\hline & $\begin{array}{l}\text { Konsistensi penulisan masih kurang dan masih } \\
\text { banyak yang typo }\end{array}$ \\
\hline & $\begin{array}{l}\text { Data diri pengembang lebih baik dibuat menu } \\
\text { tersendiri }\end{array}$ \\
\hline & $\begin{array}{l}\text { Pada menu tujuan sebaiknya dimaksukan pula } \\
\text { tujuan pengembangan }\end{array}$ \\
\hline & $\begin{array}{l}\text { Penulisan Equations Rumus matematika masih } \\
\text { banyak yang kurang sesuai }\end{array}$ \\
\hline & $\begin{array}{l}\text { Teks pada penulisan contoh soal sebaiknya tidak } \\
\text { di Bold }\end{array}$ \\
\hline & $\begin{array}{l}\text { Pada contoh soal terakhir yaitu materi lingkaran } \\
\text { tidak tersedia tombol back home }\end{array}$ \\
\hline
\end{tabular}

Penyesuaian desain dari setiap menu sebaiknya agak dibedakan, untuk menghindari kebosanan 
Range: Jurnal Pendidikan Matematika Vol. 2 No. 2 Tahun 2021 Ari Septian, dkk.

Pada bagian Kuis, sebaiknya setiap soal diacak bila pengguna memilih untuk mengulang kembali Gunakan timer pada bagian kuis

Tabel 2. Hasil Evaluasi Oleh Ahli Materi

\begin{tabular}{|c|c|}
\hline Validator & Kritik dan Saran \\
\hline $\begin{array}{c}\text { Ahli Materi } 1 \\
\text { Sarah Inayah, S.Pd.,M.Pd }\end{array}$ & $\begin{array}{l}\text { Cara menuliskan rumus sebaiknya sesuai dengan } \\
\text { gambar. }\end{array}$ \\
\hline \multirow[t]{5}{*}{$\begin{array}{c}\text { Ahli Materi } 2 \\
\text { Erwan Setiawan, S.Si, M.Si. }\end{array}$} & $\begin{array}{l}\text { Secara ide, cukup kreatif dan inovatif membuat } \\
\text { belajar matematika tidak membosankan. }\end{array}$ \\
\hline & $\begin{array}{l}\text { Konsep pembelajaran yang ditawarkan dari video } \\
\text { ini masih jadul atau masih berpatokan pada rumus, } \\
\text { jadi seperti menggiring siswa untuk hapal rumus. } \\
\text { sebaiknya kembangkan lagi agar formulasinya } \\
\text { agar siswa tidak hanya harus ngapalin rumus. }\end{array}$ \\
\hline & $\begin{array}{l}\text { Gambar-gambar yang digunakan terlalu kaku, dan } \\
\text { identitasnya tidak jelas, seperti: tidak ada } \\
\text { keterangan alas dan tinggi itu yang mana, dst. } \\
\text { sebaiknya diperjelas detail informasi gambarnya } \\
\text { sehingga siswa tidak bingung mana yang } \\
\text { dimaksud simbol t, s, x, y, dsb. }\end{array}$ \\
\hline & $\begin{array}{l}\text { Contoh yang digunakan masih bersifat abstrak. } \\
\text { karena perkembangan kedepan yang akan lebih } \\
\text { menekankan pada HOTS dan aplikasi matematika } \\
\text { dalam kehidupan sehari-hari, sebaiknya diberikan } \\
\text { contoh nyata dari setiap bangun datar yang } \\
\text { dibahas, misal persegi, berarti ada gambar keramik } \\
\text { yang bentuknya persegi,,dst. }\end{array}$ \\
\hline & $\begin{array}{l}\text { Layout atau tampilan terlalu kaku, terutama pada } \\
\text { soal dan pembahasan, sebaiknya dibuat lebih } \\
\text { menarik dengan gambar atau tulisan yang } \\
\text { berwarna-warni. }\end{array}$ \\
\hline \multirow[t]{2}{*}{$\begin{array}{c}\text { Ahli Materi } 3 \\
\text { Egi Alghifari, S.Pd }\end{array}$} & $\begin{array}{l}\text { untuk sifat - sifat dalam bangun datar tersebut } \\
\text { alangkah baiknya ditunjukan terhadap gambar atau } \\
\text { bentuk dalam bangun datar tersebut, agar siswa } \\
\text { lebih memahami dan mengetahui lebih jelas. }\end{array}$ \\
\hline & $\begin{array}{l}\text { untuk contoh terlalu monoton dengan } \\
\text { menampilkan gambar saja, tidak ada dalam bentuk } \\
\text { cerita. bisa beberapa contoh dalam bentuk yang } \\
\text { berbeda }\end{array}$ \\
\hline
\end{tabular}

Setelah dilakukan pengujian dan penilaian atau validasi oleh para ahli baik itu ahli media dan ahli materi, barulah multimedia pembelajaran matematika berbasis Macromedia flash ini akan diujicobakan di SMP Negeri1 Gekbrong. Akan tetatpi hal ini tidak terealisasi dikarenakan dampak Covid 19 yang menghambat rencana tersebut, sehingga pembelajaran siswa dan guru dilaksanakan secara daring atau pembelajaran online dari rumah. 
Validasi multimedia pembelajaran untuk ahli media dilakukan oleh tiga orang ahli media. Aspek yang dinilai oleh ahli media adalah kualitas instruksional dan kualitas teknis. Persetase hasil berdasarkan kualitas instruksional adalah 75\% dan persetase skor berdasarkan kualitas teknis adalah $79 \%$.

Hasil perhitungan data angket penilaian ahli media disajikan pada Tabel 3.

Tabel 3. Hasil Penilaian Multimedia oleh Ahli Media

\begin{tabular}{clcl}
\hline No & Kriteria Penilaian & $\begin{array}{c}\text { Persentase Skor } \\
(\%)\end{array}$ & Kategori \\
\hline 1. & Kualitas Instruksional & $75 \%$ & Layak \\
\hline 2. & Kualitas Teknis & $79 \%$ & Layak \\
\hline Rata - Rata & $78 \%$ & Layak \\
\hline
\end{tabular}

Berdasarkan Tabel 3. yaitu hasil validasi ahli media, diperoleh persentase skor rata - rata sebesar $78 \%$ dan termasuk kedalam kategori layak. Kriteria penilaian tersebut akan diuraikan sebagai berikut:(1) Kualitas Instruksional. Penilaian kualitas instruksional disajikan pada Tabel 4

Tabel 4. Hasil Penilaian Kualitas Instruksional oleh Ahli Media

\begin{tabular}{cccc}
\hline No & Aspek Penilaian & $\begin{array}{c}\text { Persentase Skor } \\
(\%)\end{array}$ & Kategori \\
\hline 1. & Kemudahan & $75 \%$ & Layak \\
\hline Rata - Rata & $75 \%$ & Layak \\
\hline
\end{tabular}

Berdasarkan Tabel 4. hasil penilaian termasuk kedalam kategori Layak. Hal tersebut menunjukkan bahwa penggunaan multimedia pembelajaran berbasis Macromedia flash ini mudah untuk digunakan. (2) Kualitas Teknis Penilaian. Kualitas teknis disajikan pada Tabel 5.

Tabel 5. Hasil Penilaian Kualitas Teknis oleh Ahli Media

\begin{tabular}{clcc}
\hline No & \multicolumn{1}{c}{ Aspek Penilaian } & $\begin{array}{c}\text { Persentase Skor } \\
(\%)\end{array}$ & Kategori \\
\hline 1. & Navigasi & $73 \%$ & Layak \\
\hline 2. & Tulisan / Teks & $81 \%$ & Sangat Layak \\
\hline 3. & Tampilan & $80 \%$ & Layak \\
\hline 4. & Teknis Pemograman & $76 \%$ & Layak \\
\hline Rata & Rata & $79 \%$ & Layak
\end{tabular}

Berdasarkan Tabel 5., aspek yang dinilai dalam multimedia yang dikembangkan ini termasuk kedalam kategori Layak. Hal tersebut menunjukkan multimedia pembelajaran matematika berbasis Macromedia flash ini mudah dijalankan sesuai dengan keinginan.

Validasi multimedia untuk ahli materi dilakukan oleh tiga orang ahli materi. Aspek yang dinilai oleh ahli media adalah kualitas instruksional dan kualitas isi dan tujuan. Persentase yang diperoleh berdasarkan kualitas instruksional adalah $72 \%$ dan persetase berdasarkan kualitas isi dan tujuan adalah 74\%. Persentase rata - rata yang perolehan dari kualitas instruksional dan kualitas isi dan tujuan adalah 73\%. Rata - rata perolehan skor tersebut dikonversikan sesuai Tabel 6. 
Tabel 6. Hasil Penilaian Multimedia oleh Ahli Materi

\begin{tabular}{llcl}
\hline No & Kriteria Penilaian & $\begin{array}{c}\text { Persentase Skor } \\
(\%)\end{array}$ & Kategori \\
\hline 1. & Kualitas Instruksional & $74 \%$ & Layak \\
\hline 2. & Kualitas Isi dan Tujuan & $72 \%$ & Layak \\
\hline Rata - Rata & $73 \%$ & Layak \\
\hline
\end{tabular}

Berdasarkan Tabel 6 terlihat bahwa hasil validasi ahli materi memperoleh persentase skor rata rata sebesar $73 \%$ dan termasuk kedalam kategori Layak. Kriteria penilaian tersebut akan diuraikan sebagai berikut (1) Kualitas Instruksional. Penilaian kualitas instruksional disajikan pada Tabel 7.

Tabel 7. Hasil Penilaian Kualitas Instruksional oleh Ahli Materi

\begin{tabular}{cccc}
\hline No & Aspek Penilaian & $\begin{array}{c}\text { Persentase Skor } \\
(\%)\end{array}$ & Kategori \\
\hline 1. & Pembelajaran & $74 \%$ & Layak \\
\hline Rata - Rata & $74 \%$ & Layak \\
\hline
\end{tabular}

Berdasarkan Tabel 7, aspek yang dinilai termasuk kedalam kategori layak. Hal tersebut menunjukkan bahwa multimedia pembelajaran matematika berbasis Macromedia flash ini mudah dimengerti (2) Kualitas Isi dan Tujuan. Penilaian kualitas teknis disajikan pada Tabel 8

\begin{tabular}{|c|c|c|}
\hline \multicolumn{3}{|c|}{ el 8. Hasil Penilai } \\
\hline Aspek Penilaian & $\begin{array}{c}\text { Persentase Skor } \\
(\%)\end{array}$ & Kategori \\
\hline Materi & $72 \%$ & Layak \\
\hline Rata - Rata & $72 \%$ & Layak \\
\hline
\end{tabular}

Berdasarkan Tabel 8, aspek yang dinilai dalam multimedia yang dikembangkan ini termasuk kedalam kategori layak. Dengan demikian, secara keseluruhan multimedia pembelajaran matematika berbasis Macromedia flash ini memiliki persentase mencapai $76 \%$ dan masuk kedalam kategori layak. Oleh karena itu multimedia pembelajaran matematika berbasis Macromedia flash ini efektif dijadikan sebagai multimedia pembelajaran yang dapat digunakan dimanapun dan kapanpun dengan menggunakan komputer atau handphone (Septian, Inayah, Suwarman, \& Nugraha, 2019).

Multimedia pembelajaran ini berbasis Macromedia flash dengan melalui model pengembangan ADDIE (Analysis, Design, Development, Implementation, and Evaluation) (Sadiyyah, Gustiana, Panuluh, \& Sugiarni, 2019). Multimedia pembelajaran berbasis macromedia ini sangat mudah digunakan karena tidak terlalu banyak tools dan menu barunya. Macromedia flash 8 didesain sebagai software yang mudah untuk dipelajari dan dipahami (Budiman \& Esvigi, 2017; Setyono, Eka, Deswita, \& Belakang, 2017).

Fungsi utama media pembelajaran adalah sebagai alat bantu mengajar yang turut mempengaruhi iklim, kondisi, dan lingkungan belajar yang ditata dan diciptakan oleh guru (Maskur et al., 2020; Rahmawati, 2018; Septian, Gustiana, \& Wulandari, 2020). Oleh karenanya media pembelajaran atau multimedia pembelajaran mampu dirancang semenarik dan seefektif mungkin sesuai dengan perkembangan zaman (Septian, Darhim, \& Prabawanto, 2020). Bentuk multimedia memungkinkan agar isinya dapat berbeda beda tergantung pengembangan yang membuat multimedia pembelajaran tersebut. Ada beberapa aspek untuk menilai atau mengevaluasi multimedia pembelajaran, diantaranya adalah aspek subject matter, auxiliary information, affective considerations, interface, navigation, pedagogy, dan robustness sehingga media tersebut dapat dikatakan layak untuk digunakan (Hendriawan \& Septian, 2019; Tahun \& Kelen, 2019). 


\section{Range: Jurnal Pendidikan Matematika Vol. 2 No. 2 Tahun 2021 Ari Septian, dkk.}

\section{Kesimpulan}

Berdasarkan uraian sebelumnya maka dapat diambil kesimpulan (1) Hasil pengembangan multimedia pembelajaran matematika berbasis Macromedia flash ini berbentuk flash dengan format .SWF yang dapat dibuka menggunakan komputer, laptop dan handphone dengan mengunakan pihak ketiga untuk komputer maupun laptop mengunakan aplikasi flash dan handphone mengunakan aplikasi webgenie SWF versi android. Multimedia pembelajaran matematika berbasis macromedia ini dikembangkan dalam materi bagun datar dan dikembangkan menggunakan aplikasi Macromedia flash dengan metode ADDIE (Analysis, Design, Development, Implementation, Evaluation). Konten - konten dalam multimedia pembelajaran matematika berbasis Macromedia flash ini menyajikan materi materi tentang bangun datar, rumus-rumus bangun datar, Sifat-sifat bangun datar, latihan soal dan kuis. (2) Hasil Penelitian secara keseluruhan, tingkat validitas teoritik multimedia pembelajaran matematika berbasis Macromedia flash ini memiliki hasil persentase mencapai $76 \%$ terdiri dari validator ahli materi dan ahli media. Dan masuk kedalam kategori layak sehingga multimedia pembelajaran matematika berbasis Macromedia flash ini layak untuk digunakan sebagai multimedia pembelajaran.

\section{Ucapan Terima Kasih}

Terima kasih kami ucapkan kepada sekolah yang telah mengijinkan kami dalam melakukan penelitian. Tak lupa pula kami sampaikan terima kasih pada pihak Universitas dan Program Studi Pendidikan Matematika Universitas Suryakancana sudah mendukung selama kami melakukan penelitian.

\section{Daftar Pustaka}

Hendriawan, M. A., \& Septian, A. (2019). Pengembangan JiMath Sebagai Multimedia Pembelajaran Matematika Berbasis Android Untuk Siswa Sekolah Menengah Atas. IndoMath: Indonesia Mathematics Education, 2(1), 45. https://doi.org/10.30738/indomath.v2i1.2785

Maskur, R., Sumarno, Rahmawati, Y., Pradana, K., Syazali, M., Septian, A., \& Palupi, E. K. (2020). The effectiveness of problem based learning and aptitude treatment interaction in improving mathematical creative thinking skills on curriculum 2013. European Journal of Educational Research, 9(1), 375-383. https://doi.org/10.12973/eu-jer.9.1.375

Masykur, R., Nofrizal, N., \& Syazali, M. (2017). Pengembangan Media Pembelajaran Matematika dengan Macromedia Flash. Al-Jabar: Jurnal Pendidikan Matematika, 8(2), 177. https://doi.org/10.24042/ajpm.v8i2.2014

Milovanović, M., Takači, urica, \& Milajić, A. (2011). Multimedia approach in teaching mathematics example of lesson about the definite integral application for determining an area. International Journal of Mathematical Education in Science and Technology, 42(2), 175-187. https://doi.org/10.1080/0020739X.2010.519800

Rahmawati, N. I. (2018). Pemanfaatan ICT dalam Meningkatkan Kemampuan Literasi Matematika. PRISMA, 1, 381-387.

Sadiyyah, R., Gustiana, M., Panuluh, S. D., \& Sugiarni, R. (2019). Pengembangan Lembar Kerja Siswa (Lks) dengan Pendekatan Inkuiri Terbimbing Berbasis Mobile Learning untuk Mengoptimalkan Kemampuan Berpikir Kritis Matematis. PRISMA, 8(1), 80. https://doi.org/10.35194/jp.v8i1.616

Seabra, C., \& Almeida, A. M. (2015). Project Management on Multimedia Projects: Preliminary Results on Communication, Interaction and Team Work Dynamics. Procedia Computer Science, 64, 816823. https://doi.org/10.1016/j.procs.2015.08.633

Septian, A. (2017). Penerapan Geogebra untuk Meningkatkan Kemampuan Pemecahan Masalah Matematis Mahasiswa Program Studi Pendidikan Matematika Universitas Suryakancana. PRISMA, 6(2). https://doi.org/10.35194/jp.v6i2.212

Septian, A., Darhim, \& Prabawanto, S. (2020). Geogebra in integral areas to improve mathematical representation ability Geogebra in integral areas to improve mathematical representation ability. 
Journal of Physics: Conference Series, 1613(2020). https://doi.org/10.1088/17426596/1613/1/012035

Septian, A., Gustiana, M., \& Wulandari, D. A. (2020). Penerapan Model Pembelajaran Kooperatif Tipe Jigsaw terhadap Peningkatan Kemampuan Koneksi. Range: Jurnal Pendidikan Matematika, 2(1), $47-55$.

Septian, A., Inayah, S., Suwarman, R. F., \& Nugraha, R. (2019). GeoGebra-Assisted Problem Based Learning to Improve Mathematical Problem Solving Ability. Advances in Social Science, Education and Humanities Research, 467(Semantik), 67-71.

Septian, A., \& Komala, E. (2019). Kemampuan Koneksi Matematik dan Motivasi Belajar Siswa dengan Menggunakan Model Problem-Based Learning (PBL) Berbantuan Geogebra di SMP. PRISMA, 8(1), 1-13. https://doi.org/10.35194/jp.v8i1.438

Setyono, T., Eka, L., Deswita, H., \& Belakang, A. L. (2017). Pengembangan Media Pembelajaran Matematika Dengan Menggunakan Macromedia Flash Pada Materi Bangun Ruang Kelas VIII Sekolah Menengah Pertama. Jurnal Fakultas Keguruan Dan Ilmu Pendidikan Universitas Pasir Pengaraian, 2(1), 1-10.

Sugiyono. (2017). Pendekatan Kuantitatif, Kualitatif, Kombinasi, R\&D dan Penelitian Evaluasi. In Metodelogi Penelitian.

Tahun, A. I., \& Kelen, Y. P. K. (2019). Upaya Meningkatkan Hasil Belajar Matematika Pada Materi Teorema Phytagoras Dengan Menggunakan Model Pembelajaran Numbered HeadsTogether ( NHT ) berbasis multimedia. Range: Jurnal Pendidikan Matematika, 1(1), 79-84.

Widyastuti, E., \& Susiana. (2019). Using the ADDIE model to develop learning material for actuarial mathematics. Journal of Physics: Conference Series, 1188(1). https://doi.org/10.1088/1742$6596 / 1188 / 1 / 012052$ 